\title{
Daily respiratory mortality and PM10 pollution in Mexico City: importance of considering place of death
}

\author{
M.M. Téllez-Rojo*, I. Romieu\#, S. Ruiz-Velasco+, M-A. Lezana , M-M. Hernández-Avila*
}

\begin{abstract}
Daily respiratory mortality and PM10 pollution in Mexico City: importance of considering place of death. M.M. Téllez-Rojo, I. Romieu, S. Ruiz-Velasco, M-A. Lezana, M. HernándezAvila. (C) ERS Journals Ltd 2000.

ABSTRACT: Significant associations have been reported between particles with a $50 \%$ cut-off aerodynamic diameter of $10 \mathrm{~mm}$ (PM10) and ozone ambient concentrations, and daily number of deaths from respiratory causes. The aim of the present study was to assess such associations among elderly ( $\geq 65 \mathrm{yrs}$ ) residents of Mexico City.

Ambient air pollution data were provided by the Metropolitan Monitoring Network. During the study period, the average daily PM10 ranged $23.4-175.3 \mu \mathrm{g} \cdot \mathrm{m}^{-3}$, and ozone $1 \mathrm{~h}$ daily maximums ranged 39.4-216.7 ppb. Information was compiled on the primary and underlying causes of death. The analyses were conducted separately according to place of death (within or out of a hospital unit) using time-series methodology.

The total number of deaths from all respiratory causes and mortality for chronic obstructive pulmonary diseases (COPD) were significantly related to PM10 over different lags: an increase of $10 \mu \mathrm{g} \cdot \mathrm{m}^{-3}$ was related to a $2.9 \%$ (95\% (CI): $0.9-4.9 \%$ ) increase and to a $4.1 \%(95 \% \mathrm{CI}: 1.3 \%-6.9 \%)$ increase with a 3-day lag when death occurred out of medical units, respectively. For deaths occurring in medical units, a longer lag and smaller risk estimate was observed. An interactive effect between PM10 and ozone was detected.

This study confirms that there is an important impact of PM10 on respiratory morbidity among elderly subjects. It also indicates that accounting for primary and underlying causes of death, and considering place of death may reduce misclassification and provide more accurate estimates of the adverse impact of PM10 on mortality. Eur Respir J 2000; 16: 391-396.
\end{abstract}

*Instituto Nacional de Salud Pública, México, "Pan American Health Organization, ${ }^{+}$Instituto de Investigación en Matemáticas Aplicadas y Sistemas, UNAM, "Dirección General de Estadśtica e Informática, Secretará de Salud, México.

Correspondence: I. Romieu, Instituto Nacional de Salud Publica, Av. Universidad \#655 Col. Sta. Ma. Ahuacatitlan C.P. 62508 Cuernavaca, Morelos, Mexico. Fax: 5273111148

\author{
Keywords: Air pollution \\ elderly \\ Mexico \\ mortality \\ ozone \\ particles with a $50 \%$ cut-off aerodynamic \\ diameter of $10 \mu \mathrm{m}$
}

Received: January 202000

Accepted after revision June 202000

This study was supported by "Departamento del Distrito Federal, Mexico", and the National Center for Environmental Health from the Centers for Disease Control and Prevention, Atlanta, GA, USA.
A series of recent studies have reported significant associations between daily number of deaths and levels of ambient air pollutants, especially levels of particulate matter. These associations have been found across a wide range of air pollutant levels and weather patterns in western countries [1-6] as well as in some developing countries [7]. However, many factors, such as particulate composition, exposure pattern, simultaneous exposure to other pollutants, and underlying health status may affect the association and explain variations in the effects observed [1, 4].

Although these reports indicate that exposure to particulate air pollution is related to short-term increases in mortality and morbidity, in general, they only include primary cause of death which provides limited information on the underlying associated causes. Such an omission will lead to an underestimation of the daily counts of specific causes of death and subsequently could lead to an underestimation of the effect of air pollution. In addition, it is likely that the place of death (within or out of a medical unit) reflects the exposure to air pollutants on the days preceding death. Therefore, it would be expected that the acute effect of air pollution on specific causes of death have a different pattern depending on the place where death occurred, particularly with regards to lag structure.
In this study, the results of a time-series study conducted in Mexico City, Mexico are reported, in which the association between mortality, due to respiratory causes, and air pollution was evaluated in an elderly population ( $\geq 65 \mathrm{yrs}$ ). Information on primary and underlying causes of death as well as on the place of death was obtained. Because Mexico City experiences high levels of both PM10 and ozone, it was possible to study the interactive effect of these pollutants on death from respiratory causes.

\section{Material and methods}

This study was carried out in Mexico City, a city of $\sim 8,600,00$ people, from January 1-December 31, 1994. The study population comprised of people age $\geq 65$ yrs who died during the study period and who lived in the city at the time of death.

Air pollution and meteorological data were provided by the automatic network of ambient monitoring of Mexico City, which comprised of 33 stations, 22 of which were located within the Distrito Federal, and 11 in surrounding areas of the city. The stations recorded daily concentrations of ozone $\left(\mathrm{O}_{3}\right)$, nitrogen dioxide $\left(\mathrm{NO}_{2}\right)$, sulphur dioxide $\left(\mathrm{SO}_{2}\right)$, and $\mathrm{PM} 10$, as well as meteorological variables such 
as temperature, relative humidity, and wind speed. These concentrations were measured in adherence with the USA Environmental Protection Agency (EPA) [4] standard methods. The study refocussed on the association of the daily variations of $\mathrm{O}_{3}$ and PM10 and deaths due to respiratory causes, because these pollutants reach high levels frequently exceeding the Mexican standard and constitute the main health concern for residents of Mexico City.

A 24-h average, and maximum 1-h and 8-h moving averages were used to reflect daily ozone levels. Particulate samplers recorded 24-h average concentrations during the study.

On the basis of statistical criteria including goodness of fit and maximum correlation, as well as on the units in which norms are stated, it was decided to use 1-h ozone daily maximum and 24-h average for PM10 in the final regression model.

The mean population exposure was estimated by averaging the measurements provided by all monitors that recorded the corresponding pollutants. The mean correlation coefficients assessed between monitoring stations were 0.43 for PM10 and 0.48 for $\mathrm{O}_{3}$.

The Ministry of Health in Mexico provided the death certificates, which included individual information such as age, sex, county of residence, place of death (in or out of a medical unit), and primary and underlying causes of death. Trained health professionals reviewed and extracted data from these certificates and categorized them by date, causes, and place of death.

To date, most of the studies relating mortality to ambient air pollution have considered only the primary cause of death [4]; however, incorporating the information on underlying causes, may help in giving a better understanding of the relationship between air pollution and death due to respiratory causes. The causes of death were classified into two groups according to International Classification of Diseases, ninth revision (ICD-9): 1) total respiratory diseases, which includes chronic obstructive pulmonary disease (COPD) (ICD-9 490-496), and lower respiratory infections (ICD-9 466, 480-487) and 2) the specific group for COPD. The outcome variables were defined as the daily number of deaths for each of these groups.

\section{Statistical Analysis}

The daily number of total respiratory deaths and the number of deaths due to COPD, and their relationship with the daily levels of $\mathrm{O}_{3}$ and PM10 were modelled using a time series analysis with Poisson regression [8].

The outcome variables were modelled controlling for long- and short-term trends that might have caused confounding [9-10], following the methodological issues proposed by ScHWARTZ et al. [11]. Long-term trends were adjusted for by controlling for cold or warm months (October-January/February-September). Short-term trends were controlled for by including in the model the minimum temperature on the day preceding death; in addition, adjustment for place of death was performed and no remaining seasonal effect was observed. When variables such as, time, month, relative humidity, day of the week and holidays were included in the model, the results remained similar; therefore, the most parsimonious model was reported.
Single pollutant models exploring different lag periods ranging 1-7 days were tested and the cumulative effect was examined by averaging levels over 3, 5 and 7 days. The effects of each pollutant were examined separately, stratifying for place of death and compared using an unpaired ttest.

To account for potential serial autocorrelation due to longitudinal data and overdispersion, the final models were estimated using the Iteratively Weighted and Filtered Least-Squares method (IWFLS), which can be considered as a generalization of the Poisson regression that takes into account these issues [12]. Since the results were very similar to those found using Poisson regression, it was decided to present those obtained with the standard technique. An outlier was detected on March 13, 1994 that showed a strong influence in the models. On that day, only one death from respiratory causes occurred, a stark contrast to the observed mean of 13.5 deaths per day; therefore, this outlier was excluded from the data.

The goodness of fit of the final model was checked using a quantile-quantile normal plot of the deviance residuals [8]. The relationship between the total mortality from respiratory causes occurring within a medical unit with a 3-day lag for PM10 adjusted for minimum temperature and cold/warm months is shown in fig. 1 . The probability distribution for the deviance residuals is close enough to a normal distribution to validate the model; the residuals of the remaining models exhibited a similar pattern. The proposed core models for deaths occurring inside and outside a medical unit reduced the total deviance by $12.23 \%$ and $14.47 \%$, respectively.

\section{Results}

Summary statistics for pollutants and meteorological variables are shown in table 1 . Of the 20,669 deaths that occurred during the study period, 4,919 (23.8\%) were attributed to respiratory causes; of these 2,294 (11.1\% of total) were due to COPD. The average number of daily respiratory deaths was 13.5 and were similarly distributed in and out of medical facilities (7.2 and 6.3 respectively). For COPD, the daily average was 6.3 and was also similarly distributed in and out of medical units (3.1 and 3.2, respectively).

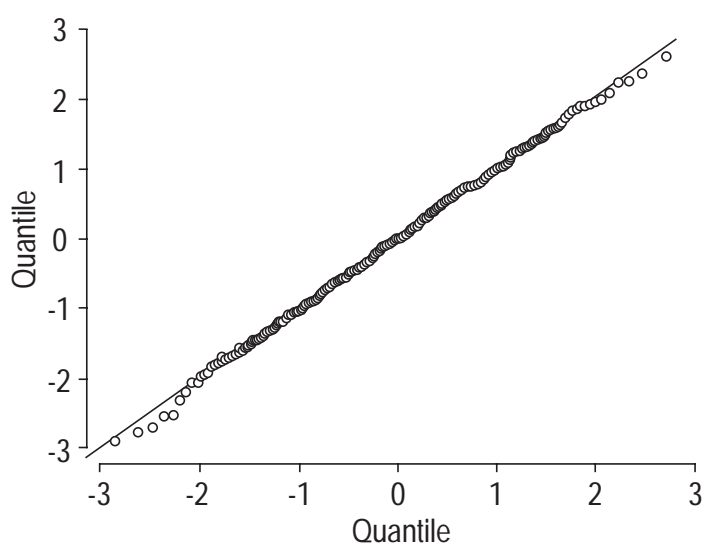

Fig. 1. - Quantile-quantile normal plot of deviance residuals for the Poisson regression model for total deaths due to respiratory causes in a medical unit, for PM10 lag 3, adjusting for minimum temperature and season. Mexico, Distrito Federal, 1994. 
Table 1. - Summary statistics for air pollutants and meterological variables in Mexico, Distrito Federal, 1994

\begin{tabular}{|c|c|c|c|c|c|c|}
\hline & \multirow[t]{2}{*}{ Range } & \multirow[t]{2}{*}{ Mean } & \multirow[t]{2}{*}{ SD } & \multicolumn{3}{|c|}{ Percentiles } \\
\hline & & & & $25 \%$ & $50 \%$ & $75 \%$ \\
\hline PM10: daily average $\mathrm{mg} \cdot \mathrm{m}^{-3}$ & $23.4-175.3$ & 75.1 & 23.7 & 58.6 & 74.4 & 88.3 \\
\hline $\mathrm{O}_{3} 1 \mathrm{~h} \max \mathrm{ppb}$ & $39.4-216.7$ & 134.5 & 33.4 & 116.7 & 135.8 & 156.6 \\
\hline $\mathrm{NO}_{2}: 1 \mathrm{~h} \mathrm{ppm}$ & $0.019-0.073$ & 0.038 & 0.010 & 0.031 & 0.037 & 0.045 \\
\hline $\mathrm{SO}_{2}:$ daily average $\mathrm{ppm}$ & $0.009-0.047$ & 0.020 & 0.005 & 0.017 & 0.019 & 0.021 \\
\hline Minimum temperature daily average ${ }^{\circ} \mathrm{C}$ & $1.5-15.8$ & 10.8 & 2.2 & 9.4 & 11.0 & 12.4 \\
\hline \multicolumn{7}{|l|}{ Total daily mortality from respiratory causes } \\
\hline Within medical unit & $0-18$ & 7.2 & 2.8 & 5 & 7 & 9 \\
\hline Out of medical unit & $1-17$ & 6.3 & 2.7 & 4 & 6 & 8 \\
\hline \multicolumn{7}{|l|}{ Daily mortality for COPD } \\
\hline Within medical unit & $0-12$ & 3.1 & 1.8 & 2 & 3 & 4 \\
\hline Out of medical unit & $0-11$ & 3.2 & 1.9 & 2 & 3 & 4 \\
\hline
\end{tabular}

PM10: particles with a 50\% cut-off aerodynamic diameter of $10 \mu \mathrm{m} ; \mathrm{O}_{3}$ : Ozone; $\mathrm{NO}_{2}$ : nitrogen dioxide.

Time series for PM10 and $\mathrm{O}_{3}$ are presented in fig. 2. During the study period the Mexican standard for $\mathrm{O}_{3}(110$ ppb 1-h maximum) was exceeded on 287 days (79\%) and the corresponding for PM10 $\left(150 \mu \mathrm{g} \cdot \mathrm{m}^{-3} 24-\mathrm{h}\right.$ average $)$ on 3 days. The $24-\mathrm{h}$ average PM10 levels exceeded $50 \mu \mathrm{g} \cdot \mathrm{m}^{-3}$ on $85 \%$ of the days. The observed correlation between $\mathrm{PM} 10$ and $\mathrm{O}_{3}$ was $0.46(\mathrm{p}<0.01)$. The highest concentrations of particulate matter, ranging $35.9-175.3 \mu \mathrm{g} \cdot \mathrm{m}^{-3}$, with a mean of $84.5 \mu \mathrm{g} \cdot \mathrm{m}^{-3}$ were registered during the cold months; during the warm months, these levels ranged $23.4-130.9 \mu \mathrm{g} \cdot \mathrm{m}^{-3}$, with a mean of $70.3 \mu \mathrm{g} \cdot \mathrm{m}^{-3}$. Ozone levels were relatively homogenous over the year. During the cold months, the levels ranged 39.4-216.7 ppb with a mean of $139.5 \mathrm{ppb}$, while during the warm months, the levels ranged 48.9-212.3 ppb with a mean of $131.9 \mathrm{ppb}$ (fig. 2).

Table 2 shows the association between air pollutant levels and the number of daily deaths caused by any respiratory disease that occurred in and out of a medical unit. Relative risks were calculated for an increase of 10 $\mu \mathrm{g} \cdot \mathrm{m}^{-3}$ for PM10 and $40 \mathrm{pbb}$ for ozone. The number of daily deaths occurring out of a medical unit was strongly associated with particulate levels; it was observed that an increase of $10 \mu \mathrm{g} \cdot \mathrm{m}^{-3}$ of PM10 levels was related to an in-

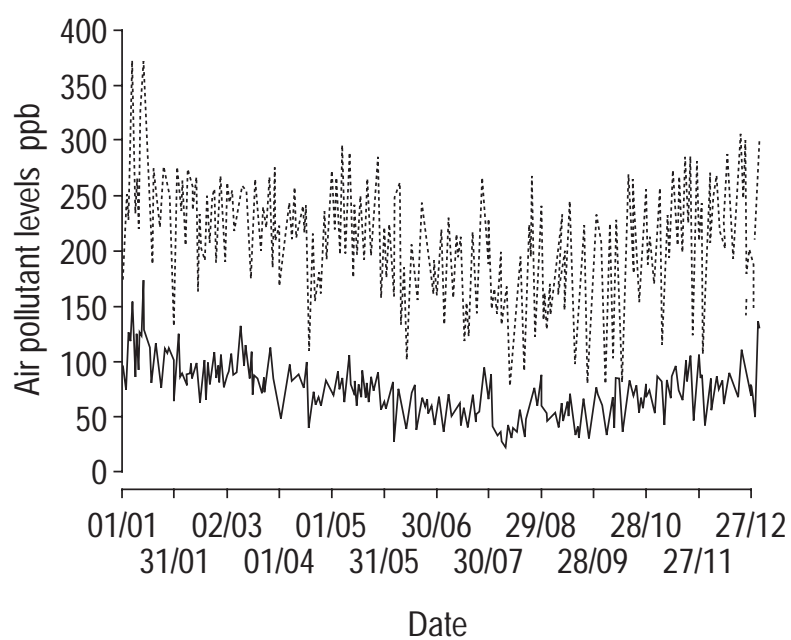

Fig. 2. - Time series of ozone and PM10 in Mexico, Distrito Federal, 1994. The $x$-axis represents the day and the month within 1994. - - - ozone, parts per billion; - : particles with a $50 \%$ cut-off aerodynamic diameter of $10 \mu \mathrm{m}, \mu \mathrm{g} \cdot \mathrm{m}^{-3}$. crease of $2.4 \%$ (95\% confidence interval (CI): $0.4 \%$, $4.5 \%)$ in the number of daily deaths occurring outside a medical unit from respiratory causes $(\mathrm{p}<0.05)$ with a 1 day lag. For lags of 2, 3, 4 and 5 days, an increase in the number of daily deaths from respiratory causes of $2.7 \%$ (95\% CI: $0.7 \%, 4.7 \%), 2.9 \%$ (95\% CI: $0.9 \%, 4.9 \%)$, $2.6 \%$ (95\% CI: $0.6 \%, 4.5 \%)$ and $2.0 \%$ (95\% CI: $0.06 \%$, $4.0 \%$ ) respectively were observed. For an increase of 10 $\mu \mathrm{g} \cdot \mathrm{m}^{-3}$ in the 5-day average PM10 levels, a significant increase of $4.2 \%(95 \% \mathrm{CI}: 1.7 \%, 6.8 \%)$ in the number of deaths from respiratory causes was observed.

The mortality pattern occurring within compared to outside a medical unit differed significantly, where lower effects and longer lag structures were observed. Increases of a 24-h average of PM10 were associated with a significant increase in the daily respiratory mortality with 5 and 7-day lags. Cumulative exposure to PM10 over 5 and 7 days was also related to mortality from respiratory causes.

A weak association between $\mathrm{O}_{3}$ levels and deaths occurring out of medical units were observed. An increase of $40 \mathrm{ppb}$ in the maximum daily 1 -h ozone level was associated with a $5.6 \%$ increase in daily mortality with a 2days lag. A significant association for cumulative exposure over 3 and 5 days was also noted, but observed no association between deaths for respiratory causes that occurred within medical units and $\mathrm{O}_{3}$ levels.

Figure 3 presents the smoothing relationship between the estimated total number of daily deaths due to respiratory illnesses occurring outside a medical unit and the 3-day lag exposure of PM10. The smooth curve was constructed using the Lowess technique [13], and suggests a linear relationship between daily mortality and PM10 over the range of ambient levels observed in this study [13].

Daily mortality for COPD presented similar patterns in the lag structure, cumulative exposure, and differences between deaths occurring in and out of medical unit than those observed for the total number of deaths from respiratory causes. However, as shown in table 3, the estimated regression coefficients were larger for deaths from COPD than those obtained for all deaths from respiratory causes. An increase of $10 \mu \mathrm{g} \cdot \mathrm{m}^{-3}$ in the daily PM10 average was related to $3.0 \%(95 \% \mathrm{CI}: 0.1 \%, 5.9 \%)$ increase in daily deaths from COPD occurring out of medical units with 1-day lag. This estimate reached $6.1 \%$ (95\% CI: $2.4 \%, 9.9 \%$ ) when a cumulative exposure over a period of 5 days was considered. For deaths due to COPD that 
Table 2. - Regression coefficients and relative risk (RR) for total number of deaths from respiratory causes adjusted for minimum temperature and season in Mexico, Distrito Federal, 1994

\begin{tabular}{|c|c|c|c|c|c|}
\hline \multirow[b]{2}{*}{ Variables } & \multicolumn{2}{|c|}{ Outside medical unit } & \multicolumn{2}{|c|}{ Inside medical unit } & \multirow[b]{2}{*}{ p-value ${ }^{\#}$} \\
\hline & $\mathrm{RR}^{*}$ & $95 \% \mathrm{CI}$ & $\mathrm{RR}^{*}$ & $95 \% \mathrm{CI}$ & \\
\hline \multicolumn{6}{|l|}{ PM10 } \\
\hline Lag 1 & 1.0244 & $1.0043-1.0448$ & 1.0157 & $0.9971-1.0347$ & 0.000 \\
\hline Lag 2 & 1.0268 & $1.0073-1.0465$ & 1.0112 & $0.9933-1.0295$ & 0.000 \\
\hline Lag 3 & 1.0286 & $1.0090-1.0486$ & 1.0156 & $0.9975-1.0341$ & 0.000 \\
\hline Lag 4 & 1.0255 & $1.0059-1.0454$ & 1.0091 & $0.9910-1.0275$ & 0.000 \\
\hline Lag 5 & 1.0201 & $1.0006-1.0399$ & 1.0236 & $1.0054-1.0421$ & 0.000 \\
\hline Avg 3 & 1.0377 & $1.0141-1.0619$ & 1.0200 & $1.0010-1.0422$ & 0.000 \\
\hline Avg 5 & 1.0422 & $1.0166-1.0684$ & 1.0245 & $1.0010-1.0485$ & 0.000 \\
\hline Avg 7 & 1.0393 & $1.0126-1.0668$ & 1.0278 & $1.0031-1.0531$ & 0.000 \\
\hline \multicolumn{6}{|l|}{$\mathrm{O}_{3}$} \\
\hline Lag 1 & 1.0173 & $0.9673-1.0699$ & 1.0378 & $0.9900-1.0879$ & 0.000 \\
\hline Lag 2 & 1.0558 & $1.0048-1.1094$ & 1.0164 & $0.9707-1.0642$ & 0.000 \\
\hline Lag 3 & 1.0359 & $0.9863-1.0880$ & 0.9978 & $0.9532-1.0444$ & 0.001 \\
\hline Lag 4 & 1.0297 & $0.9802-1.0816$ & 1.0315 & $0.9851-1.0801$ & 0.321 \\
\hline Lag 5 & 1.0403 & $0.9898-1.0934$ & 1.0228 & $0.9766-1.0712$ & 0.000 \\
\hline Avg 3 & 1.0793 & $1.0036-1.1608$ & 1.0379 & $0.9700-1.1105$ & 0.000 \\
\hline Avg 5 & 1.1403 & $1.0410-1.2490$ & 1.0686 & $0.9821-1.1628$ & 0.000 \\
\hline Avg 7 & 1.1013 & $0.9902-1.2248$ & 1.0890 & $0.9867-1.2020$ & 0.004 \\
\hline
\end{tabular}

PM10: particles with a $50 \%$ cut-off aerodynamic diameter of $10 \mu \mathrm{m}$; lag: estimate of the latency period; Avg: estimate of the cumulative exposure; $\mathrm{O}_{3}$ : ozone; $95 \% \mathrm{CI}$ : $95 \%$ confidence interval; *: relative risk was computed for an increase at $10 \mu \mathrm{g} \cdot \mathrm{m}^{-3}$ of PM10 or $40 \mathrm{ppb}$ at ozone; ": comparing coefficients from the regression models according to place of death.

occurred in medical units, the effect was significantly smaller, and the lag period was longer. The important effect of $\mathrm{O}_{3}$ ambient levels on death from COPD was smaller than that observed for PM10.

Because of the high correlation between PM10 and $\mathrm{O}_{3}$ levels, the authors studied the effect of PM10, stratifying for days with high and low $\mathrm{O}_{3}$ levels; the cut-off point used was the observed median (116.7 ppb), which is very close to the standard established by EPA [14]. No significant effect of PM10 during the days when $\mathrm{O}_{3}$ levels were low were observed (table 4); however, on days when $\mathrm{O}_{3}$ levels exceeded the cut-off point, a significant effect of PM10 on the total number of respiratory deaths and death due to COPD that occurred out of medical units was observed. This finding suggests a synergic effect of PM10 and $\mathrm{O}_{3}$

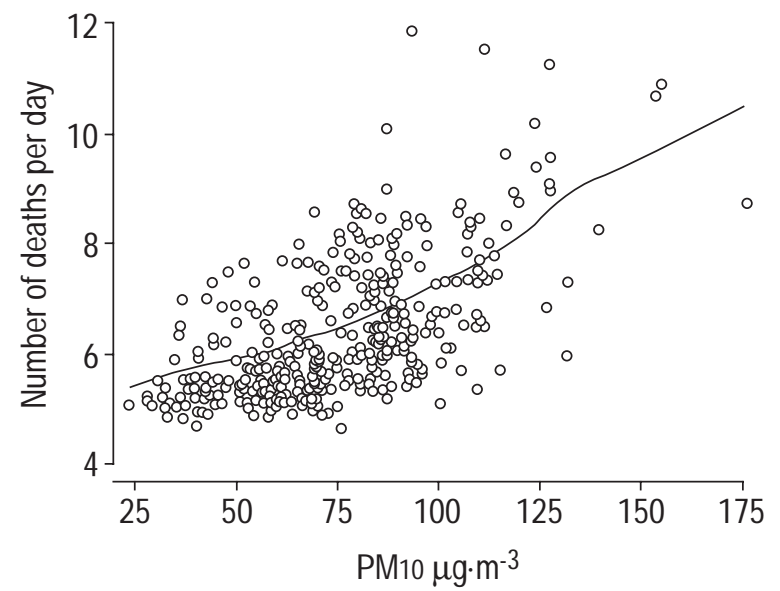

Fig. 3. - Smooth function of the number of daily death by total respiratory causes outside a medical unit and particles with a $50 \%$ cut-off aerodynamic diameter of $10 \mu \mathrm{m}$ levels with a 3-days lag. Mexico, Distrito Federal, 1994. on respiratory mortality on days when ambient $\mathrm{O}_{3}$ levels are high.

Multi-pollutant models were fitted and PM10 levels remained significantly related to respiratory mortality, but the effect of $\mathrm{O}_{3}$ was no longer significant. $\mathrm{SO}_{2}$ levels were not significantly related to respiratory deaths. When stratifying the data based on the median of $\mathrm{SO}_{2}$, no interactive effect between $\mathrm{SO}_{2}$ and PM10 was found.

\section{Discussion}

In this study, an important impact of PM10 on respiratory mortality among elderly residents of Mexico City was observed. For deaths occurring out of medical units, a 4.1\% (95\% CI: $1.3-6.9 \%)$ increase in daily COPD mortality associated with a 3-day lag increase of $10 \mu \mathrm{g} \cdot \mathrm{m}^{-3}$ in the daily average level of PM10 was observed. When cumulative exposure over 5 days was considered this estimate reached $6.1 \%$ (95\% CI: 2.4-9.9\%). The relationship appeared linear over the range of ambient levels observed in the study. For deaths occurring within the medical unit, the effects were significantly smaller and less consistent. Results also suggest an interaction between $\mathrm{PM} 10$ and $\mathrm{O}_{3}$ effects on respiratory mortality.

Several studies have investigated the association of air pollution with mortality for respiratory causes. In general, these estimates have been higher (ranging from a $1.5-3.7 \%$ per $10 \mu \mathrm{g} \cdot \mathrm{m}^{-3}$ increase in PM10) than for deaths from all causes occurring in the general population [3], especially among the elderly [2-5]. These estimations are similar to those observed in the study for deaths occurring within medical units. However, the impact of PM10 on deaths due to respiratory causes appears larger in the presented study population when one only considers those deaths that occurred out of medical facilities. There was also a longer lag effect for those deaths that occurred within 
Table 3. - Regression coefficients and relative risk (RR) for total number of deaths from chronic obstructive pulmonary disease adjusted for minimum temperature and season in Mexico, Distrito Federal, 1994

\begin{tabular}{|c|c|c|c|c|c|}
\hline \multirow[b]{2}{*}{ Variables } & \multicolumn{2}{|c|}{ Outside medical unit } & \multicolumn{2}{|c|}{ Inside medical unit } & \multirow[b]{2}{*}{ p-value ${ }^{\#}$} \\
\hline & $\mathrm{RR}^{*}$ & $95 \% \mathrm{CI}$ & $\mathrm{RR}^{*}$ & $95 \% \mathrm{CI}$ & \\
\hline \multicolumn{6}{|l|}{ PM10 } \\
\hline Lag 1 & 1.0295 & $1.0012-1.0585$ & 1.0189 & $0.9907-1.0479$ & 0.000 \\
\hline Lag 2 & 1.0403 & $1.0127-1.0686$ & 1.0191 & $0.9917-1.0472$ & 0.000 \\
\hline Lag 3 & 1.0407 & $1.0128-1.0693$ & 1.0273 & $0.9995-1.0559$ & 0.000 \\
\hline Lag 4 & 1.0350 & $1.0073-1.0635$ & 1.0249 & $0.9971-1.0534$ & 0.000 \\
\hline Lag 5 & 1.0339 & $1.0063-1.0624$ & 1.0329 & $1.0051-1.0614$ & 0.325 \\
\hline Avg 3 & 1.0525 & $1.0189-1.0872$ & 1.0304 & $0.9973-1.0647$ & 0.000 \\
\hline Avg 5 & 1.0609 & $1.0242-1.0988$ & 1.0407 & $1.0046-1.0781$ & 0.000 \\
\hline Avg 7 & 1.0556 & $1.0174-1.0952$ & 1.0422 & $1.0044-1.0814$ & 0.000 \\
\hline \multicolumn{6}{|l|}{$\mathrm{O}_{3}$} \\
\hline Lag 1 & 1.0419 & $0.9702-1.1189$ & 1.0458 & $0.9735-1.1235$ & 0.165 \\
\hline Lag 2 & 1.0452 & $0.9748-1.1207$ & 0.9903 & $0.9237-1.0617$ & 0.000 \\
\hline Lag 3 & 1.0826 & $1.0096-1.1609$ & 1.0176 & $0.9492-1.0910$ & 0.000 \\
\hline Lag 4 & 1.0017 & $0.9349-1.0733$ & 1.0559 & $0.9842-1.1328$ & 0.000 \\
\hline Lag 5 & 1.0160 & $0.9474-1.0897$ & 1.0745 & $1.0009-1.1536$ & 0.000 \\
\hline Avg 3 & 1.1279 & $1.0176-1.2503$ & 1.0405 & $0.9388-1.1531$ & 0.000 \\
\hline Avg 5 & 1.1556 & $1.0402-1.2838$ & 1.1355 & $0.9981-1.2919$ & 0.000 \\
\hline Avg 7 & 1.1191 & $0.9632-1.3003$ & 1.1628 & $1.0004-1.3516$ & 0.000 \\
\hline
\end{tabular}

PM10: particles with a $50 \%$ cut-off aerodynamic diameter of $10 \mu \mathrm{m}$; lag: estimate of the latency period; Avg: estimate of the cumulative exposure; $\mathrm{O}_{3}$ : ozone; $95 \% \mathrm{CI}$ : $95 \%$ confidence interval; *: relative risk was computed for an increase at $10 \mu \mathrm{g} \cdot \mathrm{m}^{-3}$ of PM10 or $40 \mathrm{ppb}$ at ozone; ": comparing coefficients from the regression models according to place of death.

medical units than for those occurring out of them. One explanation could be that those who died in medical units have received treatment and have been isolated from outdoor pollution. Additional information on the time spent in hospital before death would help to understand the different patterns observed between deaths occurring inside/outside medical unit; unfortunately, the authors did not have access to these data. Based on the results, it seems that the lack of stratification by place of death may lead to an underestimation of the impact of air pollution on mortality and may also obscure the lag structure. Another important factor to account for in estimating the impact of air pollution on health is the underlying cause of death. In this study, the impact of $10 \mu \mathrm{g} \cdot \mathrm{m}^{-3}$ of PM10 on deaths for respiratory causes increased from $0.6-2.9 \%$ when underlying as well as primary causes of death were considered. For deaths due to COPD these estimates raised from $2.0-4.1 \%$.

In an earlier study conducted in Mexico City, BoRJA et al. [15] reported an excess mortality of $0.5 \%$ (95\% CI: $0.3-0.7 \%$ ) associated with a $10 \mu \mathrm{g} \cdot \mathrm{m}^{-3}$ increase in total suspended particulates (TSPs) assuming that the PM10/ TSP ratio is close to 0.50 , this estimate corresponds approximately to a $1.0 \%(95 \% \mathrm{CI}: 0.6-1.4 \%)$ per $10 \mu \mathrm{g} \cdot \mathrm{m}^{-3}$ increase of PM10. For mortality from respiratory causes, (mortality that is most likely to occur among the elderly) the estimates reported would correspond to an increase of $1.9 \%(95 \%$ CI $0.3-3.6 \%)$ per $10 \mu \mathrm{g} \cdot \mathrm{m}^{-3}$ increase in the PM10 daily mean. However, in this study, TSP was only measured by one monitor over the entire city every 6 days, therefore lag effects could not be fully explored. The risk estimates reported in the study of BORJA-ABURTO

Table 4. - Particulate matter with a $50 \%$ cut-off aerodynamic diameter of $10 \mu \mathrm{m}$ (PM10) effect on daily mortality stratified for ozone levels in Mexico, Distrito Federal, 1994

\begin{tabular}{|c|c|c|c|c|c|}
\hline & & \multicolumn{2}{|c|}{ Upper ozone levels $^{\#}$} & \multicolumn{2}{|c|}{ Lower ozone levels } \\
\hline & & $\mathrm{RR}^{*}$ & $95 \% \mathrm{CI}$ & $\mathrm{RR}^{*}$ & $95 \% \mathrm{CI}$ \\
\hline \multicolumn{6}{|c|}{ Total respiratory mortality } \\
\hline \multirow[t]{2}{*}{ Outside medical unit } & PM10 (3 days lag) & 1.133 & $1.054-1.218$ & 0.973 & $0.858-1.103$ \\
\hline & PM10 (avg 5 days) & 1.173 & $1.076-1.278$ & 0.905 & $0.725-1.128$ \\
\hline \multirow[t]{2}{*}{ Inside medical unit } & PM10 (3 days lag) & 1.031 & $0.963-1.103$ & 1.090 & $0.970-1.225$ \\
\hline & PM10 (avg 5 days) & 1.058 & $0.977-1.146$ & 1.117 & $0.912-1.367$ \\
\hline \multicolumn{6}{|l|}{ COPD } \\
\hline \multirow[t]{2}{*}{ Outside medical unit } & PM10 (3 days lag) & 1.166 & $1.053-1.290$ & 0.996 & $0.831-1.193$ \\
\hline & PM10 (avg 5 days) & 1.232 & $1.092-1.391$ & 0.963 & $0.704-1.319$ \\
\hline \multirow[t]{2}{*}{ Inside medical unit } & PM10 (3 days lag) & 1.063 & $0.960-1.178$ & 1.123 & $0.938-1.344$ \\
\hline & PM10 (avg 5 days) & 1.096 & $0.971-1.237$ & 1.143 & $0.833-1.567$ \\
\hline
\end{tabular}

COPD: chronic obstructive pulmonary disease; RR: relative risk; $95 \% \mathrm{CI}$ : 95\% confidence interval; lag: estimate of the latency period; Avg: estimate of the cumulative exposure; ${ }^{\#}$ : using the median ozone level (1116.7 parts per billion) with the same lag of PM10 as a cutoff point; *: relative risk was computed for a $30 \mu \mathrm{g} \cdot \mathrm{m}^{-3}$ increase in PM10. 
et al. [15] are considerably lower than those observed in the present population. Several factors, particularly the lack of accounting for lag effect and the fact that primary and underlying causes of death were considered in the present study, may explain this difference. A more recent study, BORJA-ABURTO et al. [16], evaluated the impact of particles with a $50 \%$ cut-off aerodynamic diameter of 2.5 $\mu \mathrm{m}$ (PM2.5) on total mortality among residents of the southwest part of Mexico City; and reported that a 10 $\mu \mathrm{g} \cdot \mathrm{m}^{-3}$ increase in the level of PM2.5 was associated with a $2.5 \%$ increase in mortality among people $\geq 65$ yrs of age. Assuming a ratio of 0.7 between PM2.5 and PM10 as observed in previous studies conducted in the southwest part of Mexico City, this estimate will correspond to an increase of $3.8 \%$ in the number of deaths. This estimate is close to the results that were observed in the present study when deaths occurring outside and inside medical units were combined (3.3\% 95\% CI: $1.3-5.3 \%)$.

As observed in other studies [2-6], an exposure-response relationship between PM10 and mortality from respiratory causes, that is consistent with a monotonic increase across the range of particulates, was observed in this study. A small increase in deaths due to respiratory causes associated with $\mathrm{O}_{3}$ exposure was also observed. However, this effect was not consistent and was mostly present when exposure over several days was considered. More relevant was the interaction observed between $\mathrm{PM} 10$ and $\mathrm{O}_{3}$ on mortality from respiratory causes. When days of the study were classified according to $\mathrm{O}_{3}$ levels, it was observed that the relationship between PM10 and respiratory mortality was only significant on those days when $\mathrm{O}_{3}$ levels were high ( $\left.>116.7 \mathrm{ppb}\right)$. The cut-off point to classify low or high ozone levels was close to current EPA standards [14]. Such interaction has not previously been reported, probably because few cities have concomitant high levels of $\mathrm{PM} 10$ and $\mathrm{O}_{3}$ pollution. This interaction could also partly explain the strong effects of PM10 observed in this study.

One of the major limitations of time-series studies is that exposure is estimated at the population level and is based on ambient monitoring networks. Because of the large potential for misclassifying exposures and outcomes, it has been argued that the effects observed in this type of study is likely to underestimate the true effect [17]. Although in the present study, the estimation of exposure was based on data that was obtained from ambient monitoring stations, considering underlying as well as primary causes of death and accounting for place of death are likely to have decreased the possibility of misclassification and to have provided a more accurate estimate of the impact of air pollutants on deaths from respiratory causes in the elderly.

\section{References}

1. Thurston G. A critical review of PM10 mortality time series studies. J Expos Anal Environ Epidemiol 1996; 6: 3-2.

2. Pope CA III, Bates D, Riazenne ME. Health effects of particulate air pollution: time for reassessment. Env Health Prespect 1995; 103: 472-480.

3. Dockery D, Pope A. Epidemiology of acute health effects: summary of time-series studies. In: Particles in our air. Concentration and health effects. Wilson R, Spengler J, Eds. Cambridge, MA, Harvard University Press, 1996. pp. 123-148.

4. US Environmental Protection Agency (1996). Air quality criteria for particulate matter Vols. I-III. Washington, DC, EPA, Office of Research and Development, 1996.

5. Kelsall JE, Samet JM, Zeger SL, Xu J. Air pollution and mortality in Philadelphia 1974-1988. Am J Epidemiol 1997; 146: 750-762.

6. Schwartz J. Air pollution and daily mortality: a review and meta analysis. Environ Res 1994; 64: 36-52.

7. Romieu I, Borja-Aburto VH. Particulate air pollution and daily mortality: can results be generalized to Latin American countries. Salud Publica Mex 1997; 39: 403-411.

8. McCullagh P, Nelder JA. Generalized linear models. London: Chapman \& Hall, 1989.

9. Schwartz J, Dockery DW, Neas LN. Is daily mortality associated specifically with fine particles. J Air Waste Manage Assoc 1996; 46: 927-939.

10. Samet JM, Zeger SL, Berhane K. The association of mortality and particulate air pollution. Replication and validation of selected studies. Andover, MA, Health Effect Institute, 1995.

11. Schwartz J, Spix C, Touloumi G, et al. Methodological issues in studies of air pollution and daily counts of deaths or hospital admissions. J Epidemiol Comm Health 1996; 50: S3-S11.

12. Liang KY, Zeger SL. Regression analysis for correlated data. Annu Rev Public Health 1989; 8: 551-561.

13. Fan J, Gijbels I. Local polynomial modelling and its applications. London, Chapman \& Hall, 1996; 24-27.

14. US Environmental Protection Agency. Air Quality Criteria for Ozone and Related Photochemical Oxidants. Vol III. Washington DC, EPA, Office of Research and Development. EPA/600/P-93/004cF. July 1996.

15. Borja-Aburto VH, Loomis DP, Bangdiwala SI, Shy CM, Rascon Pacheco RA. Ozone, suspended particulates, and daily mortality in Mexico City. Am J Epidemiol 1997; 145: 258-268.

16. Borja-Aburto VH, Castillejos M, Gold DR, Bierzwinski $\mathrm{S}$, Loomis D. Mortality and ambient fine particles in southwest Mexico City, 1993-1995. Env Health Perspect 1198; 106: 849-855.

17. Hatch M, Thomas D. Measurement issues in environmental epidemiology. Env Health Perspect 1993; 101: 49-57. 